\title{
Adaptation of Induced Fuzzy Cognitive Maps to the Problems Faced by the Power Loom Workers
}

\author{
S. Narayanamoorthy \\ Dept. of Applied Mathematics, Bharathiar University, Coimbatore-46, Tamilnadu, India \\ Email:snm_phd@yahoo.co.in \\ S. Kalaiselvan \\ Dept. of Social Work, Bharathiar University, Coimbatore-46, Tamilnadu, India \\ Email:kalaiharitha@g mail.com
}

\begin{abstract}
The Indian textile industry has a significant presence in the economy as well as in the international textile economy. In this research Paper we study the socio economic problems faced by power loom workers in Avinashi in Tamilnadu, India, using Induced Fuzzy Cognitive Maps (IFCMs). We have interviewed 50 households in the study area using a linguistic questionnaire. As the problems faced by them at large, involved so much of feelings and uncertainties. We felt it to fit to use fuzzy theory in general and induced fuzzy cognitive maps in particular. For IFCMs is the best suited tool when the data is an unsupervised one.
\end{abstract}

Index Terms - Fuzzy Cognitive Maps, Induced FCMs, Power loom, Unsupervised

\section{Introduction}

Study of fuzzy theory in the context of application to the real world problems has become an important one. Still all the techniques used in the statistical analysis of any real data have no capacity to give any form of weightage to the feelings (or) attributes which ought to be associated with the problem in order to get a true situation or understanding of these problems. More so is the case in this study of power loom workers problems.

The Indian textile industry contributes twenty percent of industrial production, nine percent of excise collections, eighteen percent of employment in the industrial sector, nearly twenty percent to the country's total export earning and four percent to the Gross Domestic Product.

There are more displacement of textile workers in Power looms factory than in Sizing factory and processing factories. Power looms workers are getting wages that many workers have migrated from one place to another place. The workers were facing financial, health, housing, and social, educational and on piece rate system, they have not getting any facilities. To overcome to these problems many workers shifted to their native places. It is in this context the study attempts to examine the socio-economic problems faced by the power loom workers

The strategies of globalization and the subsequent restructuring of economies, including the increased mechanization of labor has had stifling effects on the lives of the Power loom Workers in Avinashi, in Tamil Nadu in India.

This work is based on surveys carried out in the Avinashi near Coimbatore, Tamilnadu. The data was gathered from these people using linguistic questionnaire and this linguistic questionnaire was transformed into a fuzzy data. It is important to note while doing fuzzy mathematical models the fuzzy matrix may take its entries from the interval $[-1,1]$ then also they are known as fuzzy matrices.

This paper has four sections. Introductory part is given in section one. In section two we recall the definition of fuzzy Cognitive Maps, Induced Fuzzy Cognitive Maps and its Properties .Section three is devoted to the adaptation of the Induced Fuzzy cognitive Maps to the Power loom workers. In section four we give the conclusions based on our study.

\section{FCMS And Induced FCMS}

\subsection{Basic Notions of Fuzzy Cognitive Maps}

Fuzzy Cognitive Maps are techniques that attempt to depict and analyze the cognitive process of human thinking and human behavior on specific domains by creating models. These models are represented as signed directed graphs of concepts and by the various casual relationships that exists between the concepts. In 1976 A xelrod[1] proposed cognitive maps as a formal tool for decision-making. He used the matrix representation of the directed graph to represent and 
study the social scientific knowledge. In 1986 Kosko[2] proposed FCMs based on the cognitive maps structure.

In this section we recall the notion of Fuzzy Cognitive Maps (FCMs), which was introduced by Bart Kosco[2] in the year 1986. FCMs have a major role to play main ly when the data concerned is an unsupervised one. Further this method is most simple and an effective one as it can analyze the data by directed graphs and connection matrices.

\section{Definition2.1.1}

An FCM is a directed graph with concepts like policies, events etc. as nodes and causalities as edges. It represents causal relationship between concepts.

If increase (or decrease) in one concept, leads to increase (or decrease) in another, then give the value 1. If there exists no relation between two concepts, then the value 0 is given. If increase (or decrease) in one causalities decreases (or increases) another, then give the value -1 . Thus FCMs are described in this way.

\section{Definition 2.1.2}

When the nodes of the FCM are fuzzy sets then they are called as fuzzy nodes.

\section{Definition 2.1.3}

FCMs with edge weights or causalities from the set $\{-1,0,1\}$, are called simple FCMs .

\section{Definition 2.1.4}

Consider the nodes or concepts $C_{1}, \ldots, C_{n}$ of the FCM. Suppose the directed graph is drawn using edge weight $\mathrm{e}_{\mathrm{ij}} \in\{0,1,-1\}$. The matrix $\mathrm{E}$ be defined by $\mathrm{E}=\left(\mathrm{e}_{\mathrm{ij}}\right)$, where $\mathrm{e}_{\mathrm{ij}}$ is the weight of the directed edge $\mathrm{C}_{\mathrm{i}} \mathrm{C}_{\mathrm{j}}$. E is called the adjacency matrix of the FCM, also known as the connection matrix of the FCM.

It is important to note that all matrices associated with an FCM are always square matrices with diagonal entries as zero.

\section{Definition 2.1.5}

Let $\mathrm{C}_{1}, \mathrm{C}_{2}, \ldots, \mathrm{C}_{\mathrm{n}}$ be the nodes of an FCM. $\mathrm{A}=\left(\mathrm{a}_{1}\right.$, $\left.a_{2}, \ldots, a_{n}\right)$, where $a_{i} \in\{0,1\} . A$ is called the instantaneous state vector and it denotes the on-off position of the node at an instant.

$$
a_{i}=\left\{\begin{array}{l}
0 \text { if } a_{i} \text { is OFF } \\
1 \text { if } a_{i} \text { is ON, where } i=1,2, \ldots, n
\end{array}\right.
$$

\section{Definition 2.1.6}

Let $\mathrm{C}_{1}, \mathrm{C}_{2}, \ldots, \mathrm{C}_{\mathrm{n}}$ be the nodes of an FCM. Let $\overrightarrow{C_{1} C_{2}}, \overrightarrow{C_{2} C_{3}}, \ldots, \overrightarrow{C_{i} C_{j}}$ be the edges of the FCM $(i \neq j)$. Then, the edges form a directed cycle. An FCM is said to be cyclic if it possesses a directed cycle. An FCM is said to be acyclic if it does not possess any directed cycle.

\section{Definition 2.1.7}

An FCM with cycles is said to have a feedback.

\section{Definition 2.1.8}

When there is a feedback in an FCM, i.e., when the causal relations flow through a cycle in a revolutionary way, the FCM is called a dynamical system.

\section{Definition 2.1.9}

$$
\text { Let } \overrightarrow{C_{1} C_{2}}, \overrightarrow{C_{2} C_{3}}, \ldots, \quad \overrightarrow{C_{i} C_{j}} \text { be a cycle. When } \mathrm{C}_{\mathrm{i}}
$$
is switched $\mathrm{ON}$ and if the causality flows through the edges of a cycle and if it again causes $C_{i}$, we say that the dynamical system goes round and round. This is true for any node $C_{i}$, for $i=1,2, \ldots, n$. The equilibrium state for this dynamical system is called the hidden pattern.

\section{Definition 2.1.10}

If the equilibrium state of a dynamical system is a unique state vector, then it is called a fixed point.

\section{Example}

Consider a FCM with $\mathrm{C}_{1}, \mathrm{C}_{2}, \ldots, \mathrm{C}_{\mathrm{n}}$ as nodes. For example, let us start the dynamical system by switching $\mathrm{ON} \mathrm{C}_{1}$. Let us assume that the FCM settles down with $\mathrm{C} 1$ and $\mathrm{Cn} \mathrm{ON}$ that is, the state vector remains as $(1,0$, $0, \ldots, 0,1)$. This state vector $(1,0,0, \ldots, 0,1)$ is called the fixed point.

Definition 2.1.11 
If the FCM settles down with a state vector repeating in the form $\quad \mathrm{A}_{1} \rightarrow \mathrm{A}_{2} \rightarrow \ldots \rightarrow \mathrm{A}_{\mathrm{i}} \ldots \rightarrow \mathrm{A}_{1}$, then this equilibrium is called a limit cycle.

\section{Definition 2.1.12}

We denote the combined FCM adjacency matrix by $\mathrm{E}=\mathrm{E}_{1}+\mathrm{E}_{2}+\ldots+\mathrm{E}_{\mathrm{p}}$.

Fin ite number of FCMs can be combined together to produce the joint effect of all the FCMs. Let $E_{1}, E_{2}, \ldots$, $\mathrm{E}_{\mathrm{p}}$ be adjacency matrices of the FCMs with nodes $\mathrm{C}_{1}$, $\mathrm{C}_{2}, \ldots, \mathrm{C}_{\mathrm{n}}$, then the combined FCM is got by adding all the adjacency matrices $\mathrm{E}_{1}, \ldots, \mathrm{E}_{\mathrm{p}}$.

\section{Notation}

Suppose $A=\left(a_{1}, \ldots, a_{n}\right)$ is a vector which is passed into a dynamical system $E$. Then $A E=\left(a_{1}^{\prime}, \ldots, a_{n}^{\prime}\right)$. After thresholding and updating the vector suppose we get $\left(b_{1}, \ldots, b_{n}\right)$, we denote that by $\left(a_{1}^{\prime}, \ldots, a_{n}^{\prime}\right) \hookrightarrow\left(b_{1}\right.$, $\mathrm{b}_{2}, \ldots, \mathrm{b}_{\mathrm{n}}$ ). Thus, the symbol ' $\hookrightarrow$ ' means the resultant vector has been threshold and updated.

\subsection{Algorithmic Approach in Induced Fuzzy Cognitive Maps(IFCMs)}

Even though IFCM is an advancement of FCM it follows the foundation of FCM, it has a slight modification only in Algorith mic approaches. To derive an optimistic solution to the problem with an unsupervised data, the following steps to be followed:

Step 1: For the given model (problem), collect the unsupervised data that is in determinant factors called nodes.

Step 2: According to the expert opinion, draw the directed graph.

Step 3: Obtain the connection matrix, $M$, from the directed graph (FCM). Here the number of rows in the given matrix $=$ number of steps to be performed.

Step 4: Consider the state vector $\mathrm{C}_{1}$ which is in $\mathrm{ON}$ position. Find $\mathrm{C}_{1} \times \mathrm{M}$.
The state vector is updated and threshold at each stage.

Step 5: Threshold value is calcu lated by assigning 1 for the values $>1$ and 0 for the values $<0$. The sy mbol ' $\hookrightarrow$ ' represents the threshold value for the product of the result.

Step 6: Now each component in the $C_{1}$ vector is taken separately and product of the given matrix is calculated. The vector which has maximum number of one's is found. The vector with maximum number of one's which occurs first is considered as $\mathrm{C}_{2}$.

Step 7: When the same threshold value occurs twice. The value is considered as the fixed point. The iteration gets terminated.

\section{Adaptation of Induced FCMS to the Problems Faced by the Power Loom Workers in Avinashi in Tamilnadu, India}

Now we illustrate the dynamical system by a very simple model from the problem of power loom workers. At the first stage we have taken the following seven arbitrary attributes $\left(S_{1}, S_{2}, \ldots ., S_{7}\right)$. It is not a hard and fast rule we need to consider only these nine attributes but one can increase or decrease the number of attributes according to needs. The following attributes are taken as the main nodes forstudy.

An expert system spells out the seven major concepts relating to the power loom workers as:

$$
\begin{aligned}
& S_{1}=\text { Illiteracy } \\
& S_{2}=\text { Poor salary } \\
& S_{3}=\text { Bad habits } \\
& S_{4}=\text { Lack of medical centres } \\
& S_{5}=\text { Lack of nutrients } \\
& S_{6}=\text { Poverty } \\
& S_{7}=\text { Cut-Off electricity power. }
\end{aligned}
$$

\subsection{The Directed Graph Related to the Power Loom Workers}




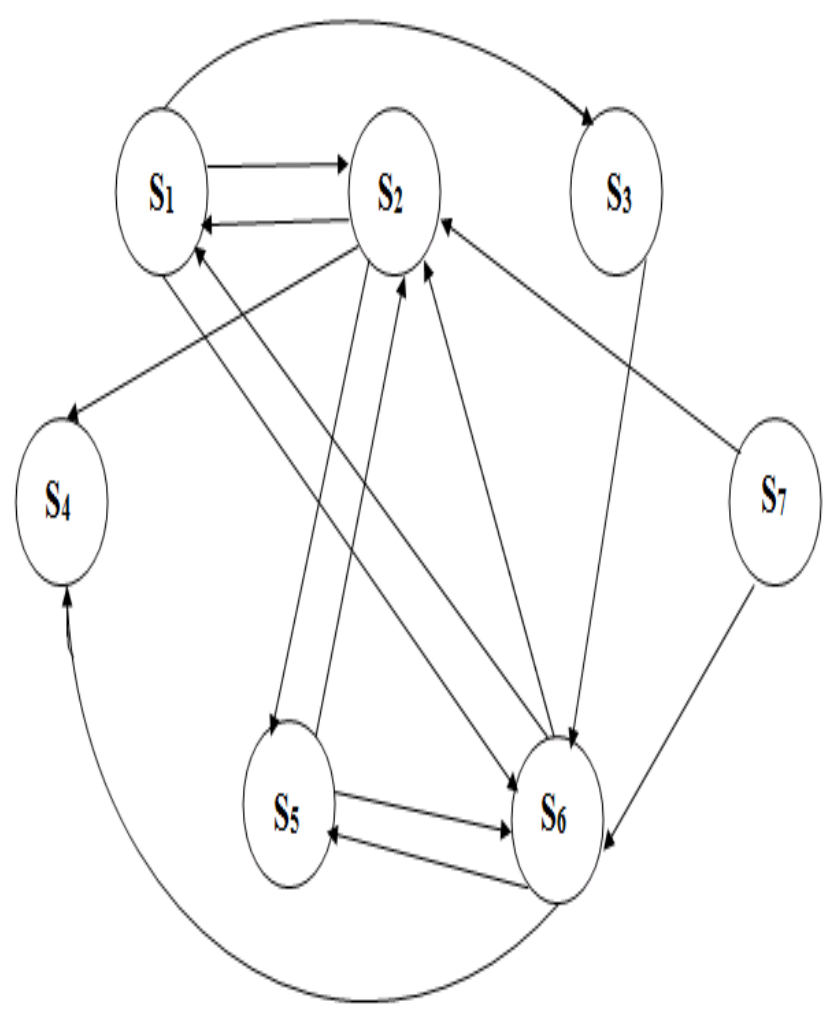

Figure 3.1: Directed Graph

\subsection{Implementation of IFCMs Model to the Study}

Based on the expert's opinion, the directed diagram is drawn and the corresponding connection matrix $\mathrm{M}$ is given as

$$
\begin{aligned}
& \begin{array}{lllllll}
\mathrm{S}_{1} & \mathrm{~S}_{2} & \mathrm{~S}_{3} & \mathrm{~S}_{4} & \mathrm{~S}_{5} & \mathrm{~S}_{6} & \mathrm{~S}_{7}
\end{array} \\
& \begin{array}{llllllll}
\mathrm{S}_{1} & 0 & 1 & 1 & 0 & 0 & 1 & 0
\end{array} \\
& \begin{array}{llllllll}
\mathrm{S}_{2} & 1 & 0 & 0 & 1 & 1 & 1 & 0
\end{array}
\end{aligned}
$$

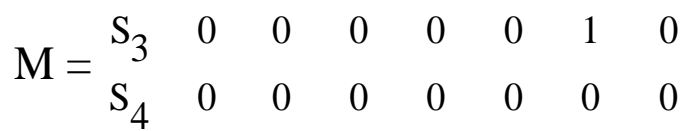

$$
\begin{aligned}
& \begin{array}{llllllll}
\mathrm{S}_{5} & 0 & 1 & 0 & 0 & 0 & 0 & 0
\end{array} \\
& \begin{array}{llllllll}
\mathrm{S}_{6} & 1 & 0 & 0 & 1 & 1 & 0 & 0
\end{array} \\
& \begin{array}{llllllll}
\mathrm{S}_{7} & 0 & 1 & 0 & 0 & 0 & 1 & 0
\end{array}
\end{aligned}
$$

Now using the matrix $M$ we determined the problems. Let us start Illiteracy is taken as the ON state and all the other nodes are in the OFF state.

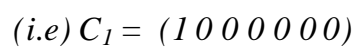

Product of $C_{1}$ and $M$ is calculated.

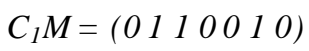

$$
\begin{aligned}
& \sim(1110010) \\
& =C_{1}^{1}
\end{aligned}
$$

Threshold value is calculated by assigning 1 for the values $>1$ and 0 for the values $<0$. The symbol ' $\hookrightarrow$ ' represents the threshold value for the product of the result.

Now as per Induced Fuzzy Cognitive Map methodology, each component in the $\mathrm{C}_{1}{ }^{1}$ vector is taken separately and product of the given matrix is calculated. The vector which has the maximum number of one's which occurs first is considered as $\mathrm{C}_{2}$.

The symbol $\sim$ denotes the calculation performed with the respective vector, here $\mathrm{C}_{1}{ }^{1}$. 


$$
\begin{aligned}
& C_{1}^{1} x M \sim(1000000) \times M \\
& \rightarrow(0110010) \\
& C_{1}{ }^{1} x M \sim(0100000) \times M \\
& \rightarrow(1001110) \\
& C_{1}{ }^{1} \times M \sim(0010000) \times M \\
& \rightarrow(0000010) \\
& C_{1}{ }^{1} x M \sim(00000010) \times M \\
& \rightarrow(1001100)
\end{aligned}
$$

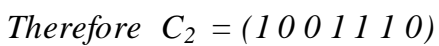

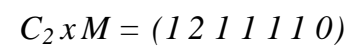

Product of $C_{2}$ and $M$ is calculated.

$$
\begin{aligned}
& \sim\left(\begin{array}{lllllll}
1 & 1 & 1 & 1 & 1 & 1 & 0
\end{array}\right) \\
& =C_{2}{ }^{1} \\
& C_{2}{ }^{1}=\left(\begin{array}{lllllll}
1 & 1 & 1 & 1 & 1 & 1 & 0
\end{array}\right) \\
& C_{2}{ }^{1} \times M=(10000000) \times M \\
& \rightarrow(0110010)
\end{aligned}
$$

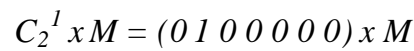

$$
\begin{aligned}
& \rightarrow(1001110) \\
& C_{2}{ }^{1} \times M=(0010000) \times M \\
& \rightarrow(0000010) \\
& C_{2}{ }^{1} \times M=\left(\begin{array}{llllll}
0 & 0 & 1 & 0 & 0 & 0
\end{array}\right) \times M \\
& \rightarrow(0000000)
\end{aligned}
$$

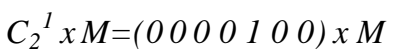

$$
\begin{aligned}
& \rightarrow(0100000) \\
& C_{2}{ }^{1} \times M=(0000010) \times M \\
& \rightarrow(1001100) \\
& \text { Therefore } C_{3}=(1001110) \\
& =C_{2} \text {. }
\end{aligned}
$$

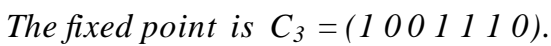

When the same threshold value occurs twice, the value is considered as the fixed point. The iteration gets terminated and the calculation gets terminated.

Likewise any state vector can be taken and its effect can be analyzed.

\section{Conclusion}

In this Section we have summarize the major findings in section three using IFCMs and interviews data.

- While analyzing with IFCMs, we observe that when Illiteracy is taken as the ON state, the resultant vector is $\left(\begin{array}{lllllll}1 & 0 & 0 & 1 & 1 & 1 & 0\end{array}\right)$.

- While analyzing with IFCMs we observe that Illiteracy, Lack of medical centers, Lack of nutrients, Poverty are the major problems to the power loom workers.

- The Cut-off electricity power is also one of the problems to the power loom workers.

- The Government should take steps to these problems.

FCMs have several advantages as well as some disadvantages. The main advantage of this method is simple. It functions on expert's opinion. When the data happens to be an unsupervised one the FCM comes handy. This is the only known fuzzy technique that gives the hidden pattern of the situation.

Although this research is unique, it has a couple of limitations also. First, the limitation of IFCM. This model consists of lengthy procedure for calculation which is not suitable for calculation with the matrices which has higher nu mber of rows and columns. Second, this manual calculation is fully based on the Expert's openion. So, it may lead to personal bias. But to deal with an unsupervised data, the IFCM model predicates the accurate results when comparing with FCM model.

\section{Acknowledgment}

The authors would like to heartily thank the anonymous reviewers for their careful reading of this paper and for their helpful comments. 


\section{References}

[1] Axelord, R., Structure of Decision: The Cognitive Maps of Political Elites, Princeton,NJ: Princeton University Press, 1976.

[2] Bart Kosko. Fuzzy Cognitive Maps, International Journal of Man-machine Studies, v24, 1986, pp. 65-75.

[3] Bart Kosko, Neural Networks and Fuzzy Systems, Prentice Hall of India Private Limited, 1997.

[4] Benjoe A. Juliano, Wylis Bandler: Tracing Chainsof-Thought (Fuzzy Methods in Cognitive Diagnosis), Physica-Verlag Heidelberg , 1996, ISBN 3-7908-0922-5.

[5] Craiger,J.and Coovert,M.D, Modeling Dyanamic Social and Psychological Processes with Fuzzy Cognitive Maps,Proceeding of the $3^{\text {rd }}$ IEEE Conference on Fuzzy Systems, v3,1994, pp.18731877.

[6] Klir, G. J., and Yuan, B., Fuzzy sets and Fuzzy logic, Prentice Hall, New Jersey, 1995.

[7] Narayanamoorthy. S, Shan mugam. P. Application of Fuzzy Networks to Analyze the SocioEconomic Problems Faced by Cotton Mill Workers.International Journal of Mathematics and Computation, 2011, pp. 28-32.

[8] Oddvar Hollup. Bonded Labour. Sterling Publishers Private Limited, 1994,New Delhi, India.

[9] Ritha. W, Mary Mejrullo Merlin. M. Predictors of interest in cosmetic surgery-An analysis using induced fuzzy cognitive maps(IFCMs). Annals of Fuzzy Mathematics and Informatics, (2), No. 2, 2011, pp.161-169.

[10] Taber, W.R., and Siegel, M. Estimation of Expert Weights with Fuzzy Cognitive Maps, Proceedings of the $1^{\text {st }}$ IEEE International Conference on Neural Networks (ICNN-87), v2,1987, pp. 319-325.

[11] Taber, W.R., Knowledge processing with Fuzzy Cognitive Maps, Expert systems with Applications, v2, 1991, pp. 83-87.

[12] Taber, W.R., Fuzzy Cgnitive Maps Model Social Systems, AI Expert, v9, 1994, pp.18-23.

[13] Tsadiras,A.K, and Margaritis, K.G., Using certainty Neurons in Fuzzy Cognitive maps, Neural Network World, v6,1996, pp.719-728.

[14] Vasantha Kandasamy, W.B, and Yasmin Sultana. Knowledge Processing using Fuzzy Relational Maps, Ultra Sci., 2000, v12, pp. $242-245$.

[15] Vasantha Kandasamy, W.B, and Anitha, V. Studies on Female Infanticide Problem using Neural Networks BAM Model. Ultra Sci., v13, 2001, pp. 174-183.
[16] Vasantha Kandasamy,W.B, Pathinathan, T,and Narayanamoorthy, S.Child labour problem in BAM model. Mathe matics and information theory: Recent topics and applications. Anmaya publishers, NewDelhi, India, 2004, pp. 62- 71.

[17] Vasantha Kandasamy, W.B., Antony Raj, S., and Victor Devadoss, A., Some new fuzzy techniques, Journal of Math \& Comp. Sci. (Math.ser.), v17, No.2, 2004, pp.157- 160 .

[18] Vasantha Kandasamy,W.B., and Smarandache Florentin., Analysis of social aspects of migrant labourers living with HIV/AIDS using Fuzzy Theory and Neutrosophic Cognitive Maps, Xiquan, Phoenix, 2004.

[19] Vasantha Kandasamy W.B, Narayanamoorthy.S., and Mary John,M, The effect of globalization on Silk weavers who are bonded labourers using Fuzzy Relational Equations, Proceedings of the KMA national seminar on Graph Theory and Fuzzy Mathematics, 2003, pp. 177-186.

[20] G. K. Venayagamoorthy, S. Doctor. Navigation of Mobile Sensors Using PSO and Embedded SO in a Fuzzy Logic Controller. IEEE 39th Industry Applications Conference. 2004, pp.1200-1206.

[21] Zedah, L.A., Fuzzy Sets, information and Control,v8,1965,pp.338-353.

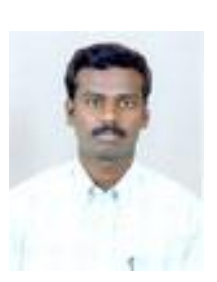

S. Narayanamoorthy was born in Tamilnadu, India in 1979. He received the B.Sc., M.Sc., M.Phil., \& Ph.D., degrees from Loyola College(Autonomous), Chennai, India, in 1999, 2001, 2002 and 2008 respectively. In 2009, he joined the Bharathiar University, Coimbatore, Tamilnadu, India, as a Assistant Professor, Department of Applied mathematics. His activities currently focus on Applications of Fuzzy Mathematics (Social Problems). His research interests include Fuzzy Optimization, Fuzzy Differential Equations.

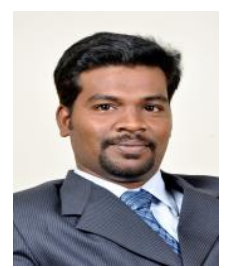

S.Kalaiselvan was born on May 20, 1986. He received the B.A. and M.S.W. degrees from Loyola College(Autonomous),Chennai, India and Bharathiar University Coimbatore, India , in 2009 and 2012, respectively.

How to cite this paper: S. Narayanamoorthy,S. Kalaiselvan,"Adaptation of Induced Fuzzy Cognitive Maps to the Problems Faced by the Power Loom Workers", International Journal of Intelligent Systems and Applications(IJISA), vol.4, no.9, pp.75-80, 2012. 